\title{
The protective effect of hydromorphone to ischemia in rat glial cells
}

\author{
Young Sung Kim ${ }^{1}$, Woon Young Kim², Yeon-hwa Kim ${ }^{3}$, Ji Won Yoo ${ }^{4}$ and Too Jae $\mathrm{Min}^{2^{*}}$
}

\begin{abstract}
Background: Ischemic insults during operation can cause ischemic-reperfusion injuries in brain as well as memory impairments. Total intravenous anesthesia (TIVA) is the preferred anesthetic method in brain surgery, as it utilizes motor evoked potential monitoring. And the use of opioids is common in TIVA. However there are few studies about ischemic protective effect of opioids to glial cells.

Methods: We used mixed cultures of rat glial cells, which were harvested from the brain of 1-day old rat. We divided the experimental groups according to their hydromorphone conditioning period: (a) pre-culture, (b) per-culture, or (c) pre- and per-culture. We measured the levels of the reactive oxygen species (ROS) induced by tert-butyl hydroperoxide (TBH) using flow cytometry. The ROS levels in the glial cells were also measured after the administration of $100 \mathrm{nM}$ hydromorphone and selective opioid receptor antagonists.

Results: The ROS levels were reduced in the hydromorphone-treated group, as compared to the control group (only TBH treated). There were no differences between pre-conditioned and per-conditioned groups. However, the ROS levels were more reduced in pre- and per-conditioned group compared to pre-conditioned or per-conditioned only groups. Furthermore, selective antagonists for the delta, kappa, or mu opioid receptor partially negated the hydromorphone effect.

Conclusion: This study demonstrated that hydromorphone can have additional protective effects on oxidative stress when pre- and per-conditioning is combined. Furthermore we proved that $\mu, \delta, k$ opioid receptors participate in protective mechanism of hydromorphone to glial cells.
\end{abstract}

Keywords: Hydromorphone, Neuroglia, Reactive oxygen species

\section{Background}

In recent times, glial cells are considered to represent a specialized functional unit with neurons, in addition to providing neuronal support. Glial dysfunction can cause cognitive disorders as well as short-term memory loss (Vicente et al. 2009; Maragakis and Rothstein 2006). Ischemic shock during surgery can induce ischemic-reperfusion injuries in the brain and memory impairments (Bilotta et al. 2013). Many studies have established that opioids are protective against ischemia and reperfusion in different cell types (Gross et al. 2010; Goldsmith et al.

\footnotetext{
*Correspondence: minware2@lycos.co.kr

2 Department of Anesthesiology and Pain Medicine, Korea University

Ansan Hospital, 123, Jeokgeum-ro, Danwon-gu, Ansan-si, Gyeonggi-do

15355, Korea

Full list of author information is available at the end of the article
}

2013). However, there are few studies that evaluate the protective effects of opioids in glial cells under ischemic conditions. Although opioids induce preconditioning effects in glial cells in the brain (Gwak et al. 2010), it is unknown whether opioids also have perconditioning effects.

Currently, total intravenous anesthesia (TIVA) is the preferred technique of anesthesia during neurosurgery due to its use of motor evoked potential (MEP) monitoring (Scheufler and Zentner 2002). The perioperative use of opioids is common in such settings. Therefore, it is meaningful to investigate whether opioids possess preand per-conditioning effects on glial cells. In this study, we evaluated whether hydromorphone had pre- and perconditioning effect on glial cells. Furthermore we sought 
to determine whether hydromorphone had additive effects when pre- and per-conditioning were combined.

\section{Methods \\ Chemicals}

Hydromorphone was purchased from Hanapharm Co. (Seoul, Korea). Tert-butyl hydroperoxide (TBH, $\mathrm{t}-\mathrm{BOOH}$ ) and $2^{\prime}, 7^{\prime}$-dichloroflurorescin diacetate (DCFDA) were purchased from Sigma Chemical Co. (St Louis, MO, USA). The anti-glial fibrillary acidic protein (GFAP) primary antibody and Alexa Fluor 488 goat anti-mouse antibody were purchased from Millipore Co. (Billerica, MA, USA) and Invitrogen Co. (Carlsbad, CA, USA), respectively. XTT was purchased from WELLGNE Inco. (Dalseo-gu, Daegu, Republic of Korea). The mounting solution was purchased from Vector Laboratories (Burlingame, CA, USA).

\section{Mixed primary rat glial cell culture}

Rat glial cells were harvested and purified by the methods of previous study (de Vellis and Cole 2012). Pregnant Sprageue Dawley rat were purchased from Orientbio Co. (Seongnam-si, Gyeonggi-do, Republic of Korea). The rat cerebral cortices were purified from the brains of 1-day old rat pups, and then cultured in Dulbecco's modified Eagle's medium (DMEM) media supplemented with $10 \%$ fetal bovine serum, $1 \%$ antibiotics at $37{ }^{\circ} \mathrm{C}$, and $5 \% \mathrm{CO}_{2}$ for 2 weeks. After 2 weeks, neurons, meningeal cells and fibroblasts were diminished, meanwhile microglial cells and astrocytes were replaced. We confirmed by immunostaining with anti-GFAP primary antibody via confocal microscope (Nikon A1si, Nikon, Japan). All procedures were reviewed and approved by the Committee on the Ethics of Animal Experiments of the Korea University Medical School. (IRB KUIACUC-2015-253)

\section{Cell viability}

Cell viability was measured by XTT (2,3-bis-2-methoxy4-nitro-5-sulfophenyl-2H- tetrazolium-5-carboxanilide inner salt, WelCount Cell Viability Assay kit). The mixed glial cells were cultured in a 96-well plate. The control, TBH $(100 \mu \mathrm{M})$ and/or hydromorphone $(100 \mathrm{nM})$ treated glial cells were placed in a new DMEM media, containing a $5 \%$ XTT reaction mixture $(50: 1=$ XTT solution: PMS solution) and incubated in a $\mathrm{CO}_{2}$ incubator, at a temperature of $37^{\circ} \mathrm{C}$ for a period of $2 \mathrm{~h}$. The XTT assay generated formazan crystals, which were measured spectro-photometrically with an ELISA reader $(690 \mathrm{~nm})$.

\section{Experimental protocol}

The production of ROS in mixed glial cells was induced by TBH, which is organic peroxide (Peters et al. 2001), and then ROS was measured by flow cytometry using DCF-DA. The glial cells were proliferated to $5 \times 10^{4}$ cells in 6-well plates, and then transferred to a serum-free media, which was prepared by overnight serum starvation. The cells were divided into 4 experimental groups : (1) pre-culture period (administration of $100 \mathrm{nM}$ hydromorphone for $1 \mathrm{~h}$, and then the media was changed to a serum-free media prior to $100 \mu \mathrm{M}$ of TBH administration.); (2) per-culture period (100 $\mathrm{nM}$ of hydromorphone and $100 \mu \mathrm{M}$ of $\mathrm{TBH}$ were co-treated.); (3) pre- and perculture $(100 \mathrm{nM}$ of hydromorphone was pretreated for $1 \mathrm{~h}$, and then the media was changed to a serum-free media. In addition, $100 \mu \mathrm{M}$ of TBH and $100 \mathrm{nM}$ of hydromorphone co-administrated for $30 \mathrm{~min}$.); and (4) opioid receptor antagonist groups (pretreatment of $100 \mathrm{nM}$ hydromorphone for $1 \mathrm{~h}$, along with a selective delta- $(\delta-)$, kappa- (к-), or mu-( $\mu-)$ opioid receptor antagonist, then cells were co-treated with $\mathrm{TBH}$, opioid receptor antagonist, and $100 \mathrm{nM}$ of hydromorphone) (Fig. 1). The dosage of opioid receptor antagonists were determined by previous study (Min et al. 2011). Also, Pilot study for determining the dosage of hydromorphone was performed. Three different doses $(10,100,1000 \mathrm{nM})$ of hydromorphone were administrated. Each dosage of hydromorphone was treated for $1 \mathrm{~h}$ before $100 \mu \mathrm{M}$ of TBH treatment (Fig. 2).

\section{The measurement of the intracellular reactive oxygen species (ROS) production \\ Flow cytometry}

The control-, TBH- $(100 \mu \mathrm{M})$ and/or hydromorphone$(100 \mathrm{nM})$ treated glial cells were incubated in a $\mathrm{CO}_{2}$ incubator with DCF-DA $(10 \mu \mathrm{g} / \mathrm{ml})$ at $37{ }^{\circ} \mathrm{C}$ for $20 \mathrm{~min}$. The DCF-DA-treated glial cells were washed with phosphatebuffered saline (PBS) and detached from the plate using trypsin-EDTA (0.25\%). The detached cells were diluted with PBS (300 $\mu \mathrm{l})$ for analysis by flow cytometry. At least three different sets of experiments were performed using cells from different isolations.

\section{TUNEL assay for apoptosis detection in glial cells}

Apoptosis is characterized by DNA fragmentation, which can be detected by selective staining. A terminal deoxynucleotidyltransferase-mediated dUTP nick end labeling (TUNEL) apopto-sis staining kit (Roche Molecular Biochemicals, Mannheim, Ger-many) was used to detect programmed cell death. The glial cells were treated with hydromorphone $(100 \mathrm{nM})$ for the pre-/per-period with TBH $(100 \mu \mathrm{M})$ for $30 \mathrm{~min})$, followed by fixation and TUNEL staining. The fixed cells were washed 3 times with PBS containing $0.1 \%$-Tween 20 . The en-zyme and label solutions in the TUNEL stain kit were thoroughly mixed and reacted at $37^{\circ} \mathrm{C}$ for $1 \mathrm{~h}$. After the re-action, 


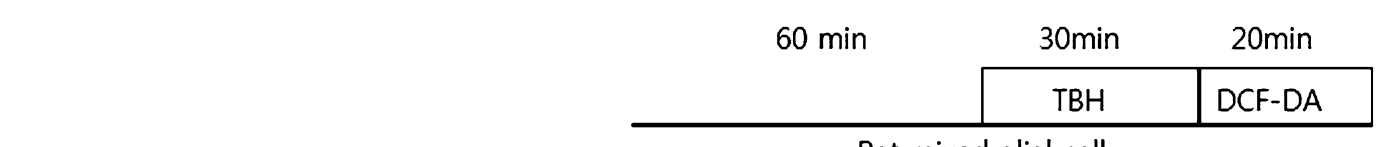

Control group

Preconditioning group (pre 100nM hydromorphone)

Perconditioning group (100 nM hydromorphone)

Pre + Per-conditioning group

Opioid Receptor blocker group
Rat mixed glial cell

\begin{tabular}{|c|c|c|}
\hline $60 \min$ & $30 \mathrm{~min}$ & $20 \mathrm{~min}$ \\
\hline Hydromorphone & $\mathrm{TBH}$ & DCF-DA \\
\hline
\end{tabular}

Hydromorphone added

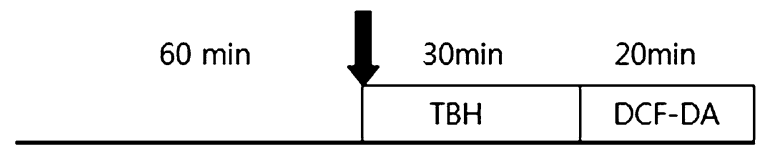

Rat mixed glial cell

Hydromorphone + TBH added

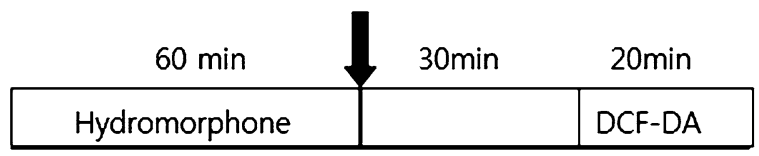

Rat mixed glial cell

Hydromorphone/OR blocker + TBH added

\begin{tabular}{|c|c|c|}
\hline $60 \min$ & $30 \mathrm{~min}$ & $20 \mathrm{~min}$ \\
\hline Hydromorphone/OR blocken & & DCF-DA \\
\hline
\end{tabular}

Rat mixed glial cell

Fig. 1 Experimental design. TBH: tert-butyl hydroperoxide, DCF-DA: 2',7'-dichloroflurorescin diacetate, OR antagonist : naltrindole (a selective delta opioid receptor antagonist) or nor-binaltorphimine (a selective kappa opioid receptor antagonist) or naloxone

the cells were washed 3 times with PBS containing $0.1 \%$-Tween 20 and then examined using a confocal micro-scope. Three slides were examined for each group, and then particles were counted from 10 different parts of each slide.

\section{Statistical analysis}

We used SPSS (Windows version 10.0, Chicago, IL, USA) for statistical analysis. All results are expressed as a mean \pm standard deviation (SD) and are representative of three different experiments. The flow cytometry results were evaluated by one-way Anova. $P$ values greater than 0.05 were considered significant.

\section{Results}

Cell viability

The cell survival rate after TBH was $84 \%$. This was calculated as a mean value.

\section{Hydromorphone dosage}

The cells that were treated with 100 or $1000 \mathrm{nM}$ of hydromorphone had significantly lower levels of ROS 


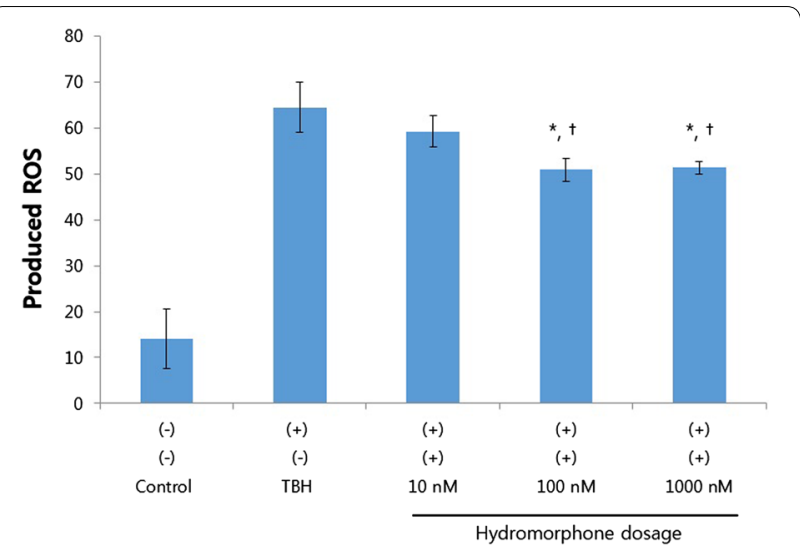

Fig. 2 This graph shows effective dosage of hydromorphone for reducing ROS. The amount of ROS was expressed as Mean Fluorescence index. ${ }^{*}<0.05$ versus TBH group. ${ }^{\dagger}<0.05$ versus $10 \mathrm{nM}$ hydromorphone group

compared to those in the TBH-treated group (Fig. 2). There were no differences between ROS levels in the 100 and $1000 \mathrm{nM}$ groups.

\section{The effects of TBH and/or hydromorphone on reactive oxygen species (ROS) production}

The ROS production was lower in the hydromorphonetreated group compared to the control group treated with TBH only. Moreover, the ROS production was significantly lower in the pre- and per-conditioned groups compared to the pre-conditioned or the per-conditioned alone groups (Fig. 3).

\section{The effect of opioid antagonists on reactive oxygen species (ROS) production}

The production of ROS was reduced in the hydromorphone-treated group. However, each of the selective $\delta$-, $\kappa-$, and $\mu$-opioid receptor antagonists partially negated the hydromorphone effects on ROS production (Fig. 4).

\section{TUNEL assay in glial cells}

The apoptotic cells appeared as light red dots under a fluorescent microscope after performing the TUNEL as-say. A comparison between the TBH group and the pre- and perconditioned group revealed that there were significantly less apoptotic cells in the pre- and per-conditioned group. Furthermore, the number of apoptotic cells in the opioid receptor blocker group was significantly increased (Figs. 5, 6).

\section{Discussion}

Currently, TIVA is the preferred method for general anesthesia during cerebral surgery because TIVA barely affects MEP monitoring (Zhang et al. 2011, 2004). Opioid use for intra-operative analgesia is common in TIVA. In this study, we demonstrated the pre-conditioning and per-conditioning effects of hydromorphone, providing evidence for the peri-operative effectiveness of hydromorphone.

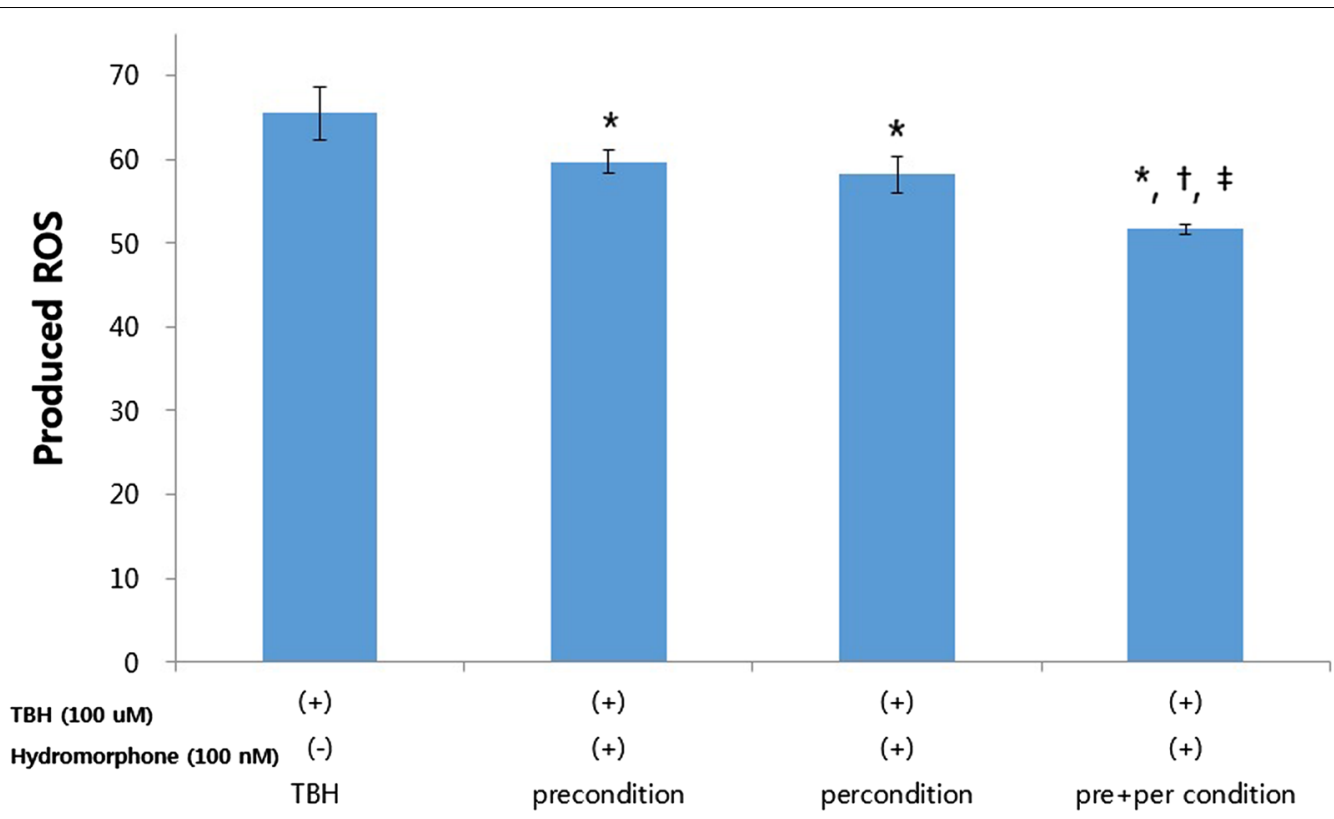

Fig. 3 Detection of intracellular ROS (reactive oxygen species) product. This graph shows the protective effect of hydromorphone on TBH induced toxicity in primary rat glial cell cultures. The ROS level was measured with using FACS (DCF-DA) in the 100 nM hydromorphone (1) pre conditioned (2) per-conditioned (3) pre- and per-conditioned primary rat glial cells. The amount of ROS was expressed as Mean Fluorescence index. ${ }^{*}<0.05$ versus TBH group. ${ }^{\dagger}<0.05$ versus preconditioning group. ${ }^{\ddagger}<0.05$ versus perconditioning group 


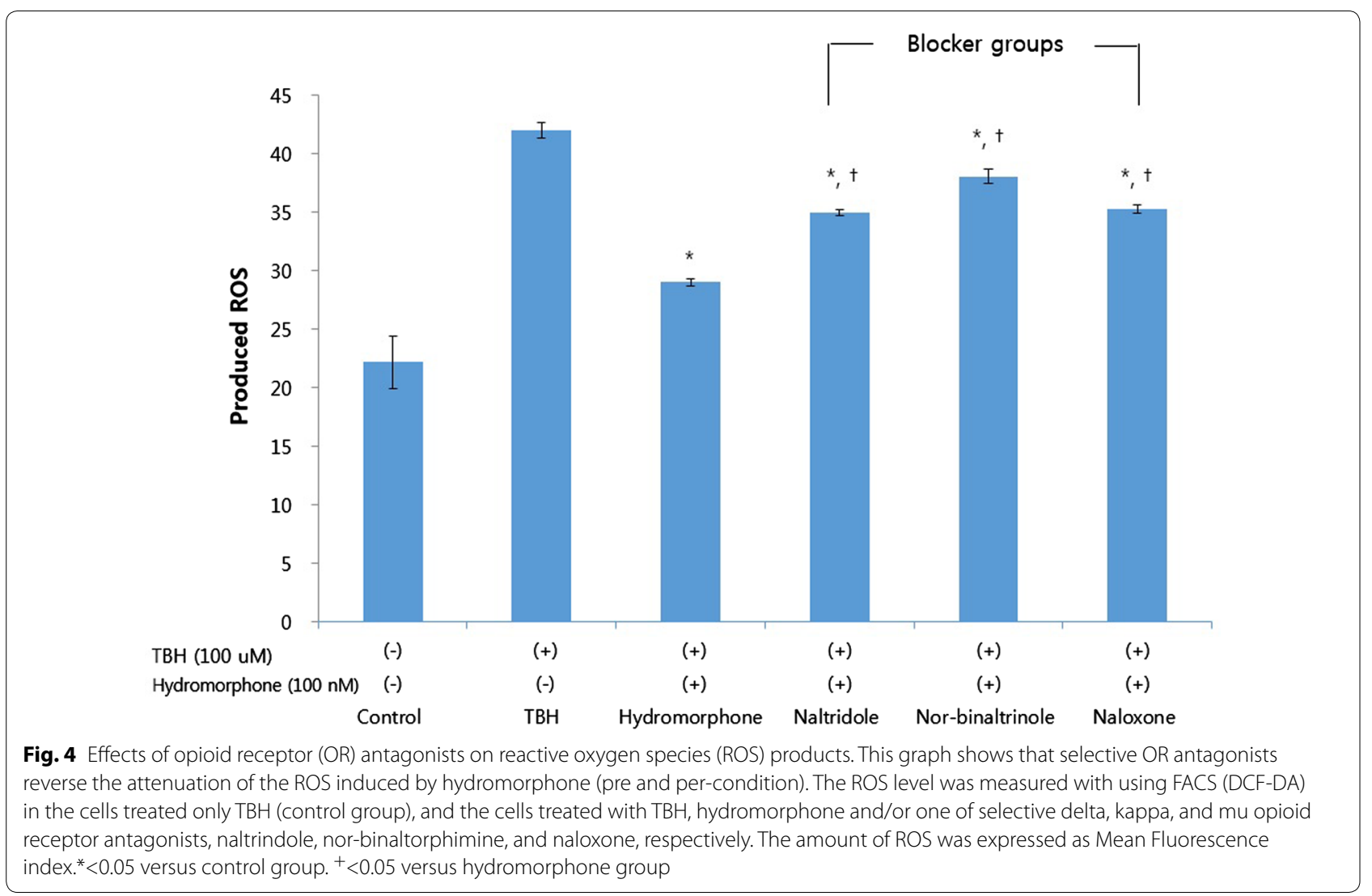

Recent studies have shown that opioids, including morphine, have protective preconditioning effects in several ischemia/reperfusion models (Zhang et al. 2011, 2004). Morphine has anti-neuroinflammatory properties and can prevent memory deficits due to its preconditioning effect, which is dependent on opioid receptors (Rostami et al. 2012). However, the role of opioids in glial cells is unclear. Although glial cells play an important role in the antioxidant defense system in the brain (Iwata-Ichikawa et al. 1999), they are considered to be functional units rather than the barriers of neurons. Glial cell dysfunction can cause cognitive impairments and short-term memory loss (Vicente et al. 2009; Maragakis and Rothstein 2006). In addition, neuroinflammation is highly associated with ischemic stroke-induced cerebral damage and the progression of neurodegenerative diseases (Mucke and Eddleston 1993; Kreutzberg 1996; Brown and BalPrice 2003). Glial cells are important because they are responsible for the brain's neurophysiology and hence, represent potential therapeutic targets.

Excessive oxidative stress produces excessive ROS. These ROS play important roles to CNS damage during ischemic conditions (Kontos 1989) and are associated with a variety of diseases ( $\mathrm{Hu}$ et al. 2015). Although a certain amount of ROS is essential for cellular survival, cell death can occur when ROS-induced oxidative stress exceeds a cell's antioxidant capabilities ( $\mathrm{Hu}$ et al. 2015; Yan 2014). Excessive ROS production can cause DNA damage, modify protein and lipid functions, and activate signal pathways (Yan 2014). However, a moderate level of oxidative stress, referred to as positive oxidative stress, can be induced and modulated to produce an adaptive cellular response that is beneficial for cellular survival. Both preconditioning and per-conditioning effects can potentially be the result of positive oxidative stress (Yan 2014; Milisav et al. 2012). Brief episodes of ischemia and reperfusion, and a number of pharmacological agents, can induce these phenomena (Das and Das 2008). TBH is commonly used to induce oxidative stress in vitro and in vivo (Rush et al. 1985). In this study, we used TBH to induce oxidative stress-related injury to rodent-derived glial cells (Holownia et al. 2009).

Several studies have demonstrated that morphine is involved in immune system functions (Hutchinson et al. 2007; Madera-Salcedo et al. 2011). Morphine exhibits both peripheral anti-inflammatory and inflammatory roles (Askari et al. 2008; Pourpak et al. 2004). Although opioids can induce glial activation and neuroinflammatory reactions (Watkins et al. 2009), morphine-induced preconditioning has been found to be 
a

Rhodamin

Rhodamin (Merge)

b

DAPI

TBH(100uM)

Hydromorphone (100nM)

Rhodamin

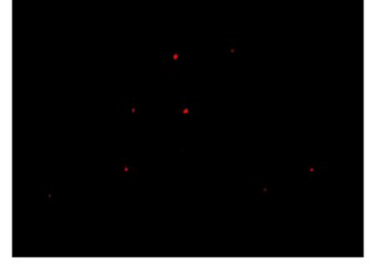

DAPI

$+$

Rhodamin

(Merge)

TBH(100uM)

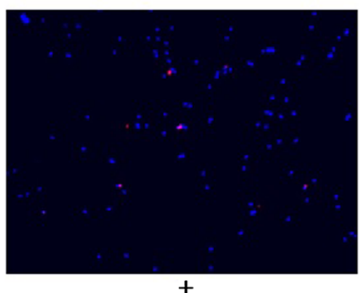

Hydromorphone (100nM)

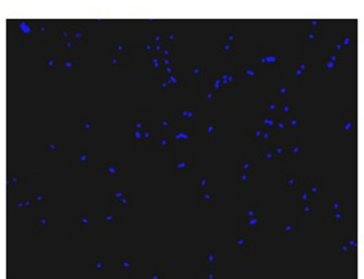

\section{TUNEL Assay}
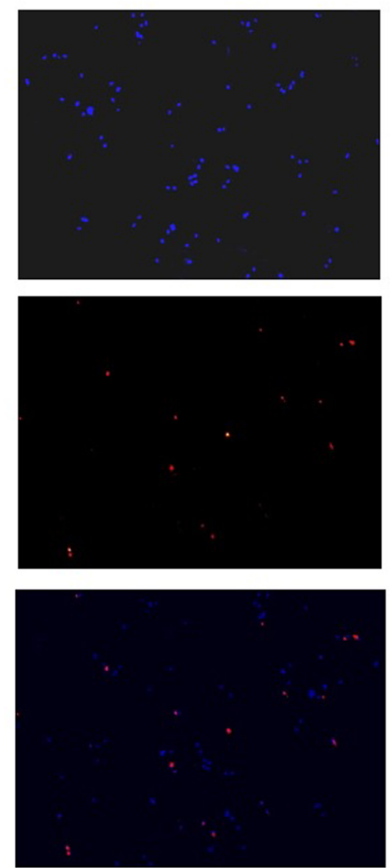

$+$

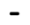

$\mathrm{TBH}$
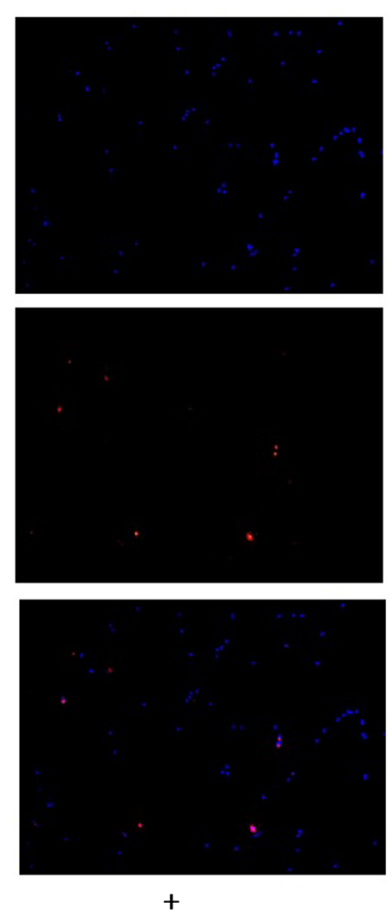

$+$

Hydromorphone

\section{TUNEL Assay for opioid antagonists}
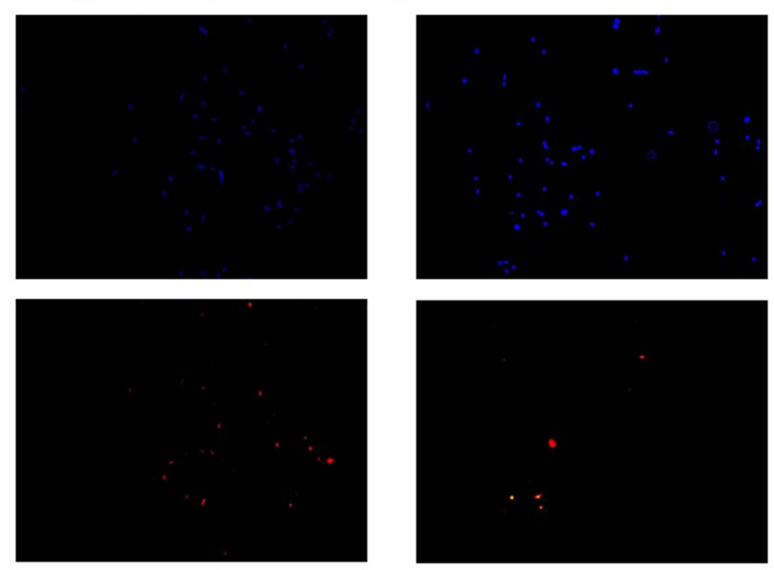

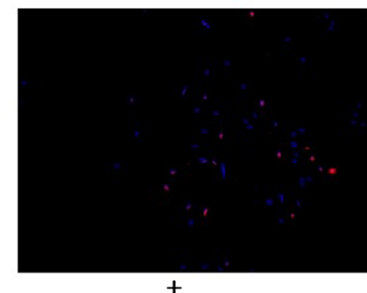

$+$

$+$

Norbinaltorphimine

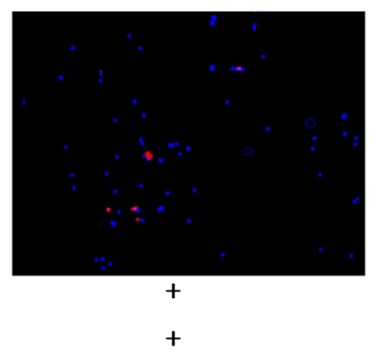

Naltridole 
(See figure on previous page.)

Fig. 5 Terminal deoxynucleotidyl transferase-mediated dUTP nick end labeling (TUNEL) assay of rat glial cells. a Fluorescence micrographs of cells were stained with rhodamine and DAPI. Red particles represent DNA fragments. This graphs show the Control, TBH, and Hydromorphone groups. b Fluorescence micrographs of cells were stained with rhodamine and DAPI. Red particles represent DNA fragments. This graphs show the opioid antagonist groups. ${ }^{\dagger}<0.05$ versus hydromorphone group

anti-neuroinflammatory (Rostami et al. 2012). In these studies, we used hydromorphone, an opioid receptor agonist and morphine derivative (Ricket et al. 2015), to prevent TBH-induced ROS production. Hydromorphone, one of the first line opioids as per the European guideline (Oosten et al. 2015), is widely used for acute and chronic pain management in both adults and children (Oosten et al. 2015; Mherekumombe and Collins 2015). Compared to morphine, hydromorphone has certain clinical advantages, such as reduced nausea and vomiting (Wirz et al. 2008), and lower histamine release (Guedes et al. 2007). To demonstrate its protective effect, we used hydromorphone to induce oxidative stressrelated injury. Because there are few in vitro studies using hydromorphone, we choose an equi-analgesic dosage of hydromorphone as compared to morphine, based on previous studies (Min et al. 2011; Lee et al. 2012). Pilot studies determined the maximum effective dose of hydromorphone for a pre-/per-conditioning effect, which was $100 \mathrm{nM}$ (Fig. 1).

In this study, hydromorphone was protective against $\mathrm{TBH}$-induced oxidative stress-related injury. Interestingly, the combined administration of hydromorphone (pre-conditioning followed by co-administration) had a superior effect compared to pre-conditioning and coadministration treatments alone. Opioids can not only suppress responses to various noxious stimuli (e.g., short cyclic episodes of ischemia or ROS), but also have similar pre-conditioning effects (Rostami et al. 2012; Das and Das 2008). This cumulative effect of hydromorphone may be important for clinical settings, such as the perioperative use of hydromorphone in neurosurgery.

The endogenous opioids and their receptors $(\mu-, \delta$-, $\kappa-)$ are widely distributed in the glials like astrocytes (Pearce et al. 1985), oligodendrocytes (Knapp et al. 1998) and microglial cells (Calvo et al. 2000; TurchanCholewo et al. 2008). They exert their physiological effects, including nociception, analgesia, and brain development. Recently, Jeong et al. (2012) reported that remifentanil which is selective agonist for $\delta$-opioid receptor, has neuroprotective effect to both neurons and glial cells, improves neurological scores, and reduces infarct volumes via the attenuation of mitogen-activated protein kinases (MAPK). MAPK involves ROS production and the release of pro-inflammatory cytokines (Son et al. 2011). But the protective effects of $\mu$ - and $\kappa$-opioid receptors to cerebral ischemia are still controversial. Some of studies have elucidated the protective function of $\kappa$-opioid receptors to reperfusion injury in ischemic cerebral animal models (Zhang et al. 2003; Goyagi et al. 2003). These effects are mediated through reducing NO production. Goyagi et al. (2003) showed that
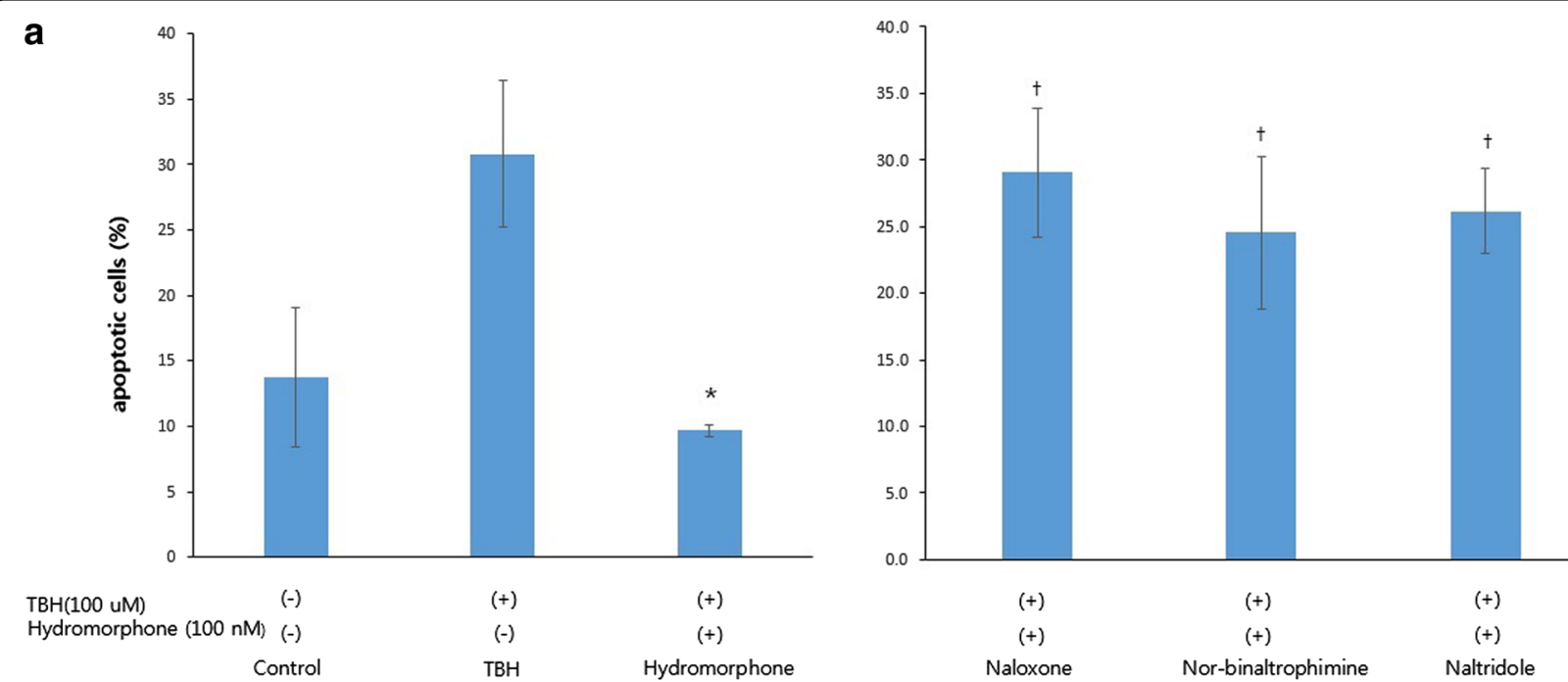

Fig. 6 Terminal deoxynucleotidyl transferase-mediated dUTP nick end labeling (TUNEL) assay of rat glial cells. a This graph shows quantitation of apoptotic cells from TUNEL assay by number of red particles. ${ }^{*}<0.05$ versus TBH group. ${ }^{\dagger}<0.05$ versus hydromorphone group 
activation of $\mathrm{k}$-opioid receptors attenuates the evokation of NMDA by inhibiting excitatory postsynaptic potentials, and NMDA is involved in the NO production of brain. NMDA receptors are abundant in glial cells and neurons, and have important roles to maintain the homeostasis of brain (Verkhrataky and Kirchhoff 2007). These evoked $N$-Methyl-D-aspartic acid (NMDA) also induces ROS products (Shelat et al. 2008). Our results demonstrate that each opioid receptor subtype, the $\mu$-, $\delta$-, and $\kappa$-opioid receptor, reduces ROS production and is involved in the protective effects of hydromorphone in mixed glial cells. After administration of selective $\mu-, \delta$, and $\mathrm{K}$-opioid receptor antagonists, ROS production was similar to that of the TBH-treated group, suggesting that the $\mu$-, $\delta$-, and $\kappa$-opioid receptors all contribute to hydromorphone's protective effects. Our data also suggest that hydromorphone has pre and per conditioning effects as well. Considering the present results, MAPK pathways and NMDA signaling pathways might be involved in the protective effect of hydromorphone on $\mathrm{TBH}$-induced glial cells. Further studies are required to evaluate the mechanism underlying opioid receptors involvement by using knockout models.

In conclusion, this study provides evidence that hydromorphone has both, pre-conditioning and per-conditioning effects on the TBH-induced injuries. Furthermore, pre- and per-conditioning effects of hydromorphone is additive. We also demonstrated that the $\mu$-, $\delta$-, and $\kappa$-opioid receptors all contributes to the mechanism of hydromorphone and its protective effect on glial cells. Hence, our findings support the therapeutic potential for hydromorphone in the prevention of ischemic cerebral injury during the perioperative period.

\section{Abbreviations}

TBH: tert-butyl hydroperoxide; ROS: reactive oxygen species; TIVA: total intravenous anesthesia; MEP: motor evoked potential.

\section{Authors' contributions}

All authors contributed in the overall process of the experiment. Supported by Korea University Medical School. All authors read and approved the final manuscript.

\section{Author details \\ ${ }^{1}$ Department of Anesthesiology, Korea University College of Medicine, Seoul, Korea. ${ }^{2}$ Department of Anesthesiology and Pain Medicine, Korea University Ansan Hospital, 123, Jeokgeum-ro, Danwon-gu, Ansan-si, Gyeonggi-do 15355, Korea. ${ }^{3}$ Institute of Medical Science, Korea University Ansan Hospital, Korea University College of Medicine, Ansan, Korea. ${ }^{4}$ Department of Internal Medi- cine and Institute of Gerontology, University of Nevada, School of Medicine, Las Vegas, NV, USA.}

\section{Competing interests}

The authors declare that they have no competing interests.

Received: 4 February 2016 Accepted: 5 May 2016

Published online: 12 May 2016

\section{References}

Askari N, Mahboudi F, Haeri-Rohani A, Kazemi B, Sarrami R, Edalat R, Ahmadiani A (2008) Effects of single administration of morphine on G-protein mRNA level in the presence and absence of inflammation in the rat spinal cord. Scand J Immunol 67(1):47-52. doi:10.1111/j.1365-3083.2007.02043.x

Bilotta F, Gelb AW, Stazi E, Titi L, Paoloni FP, Rosa G (2013) Pharmacological perioperative brain neuroprotection: a qualitative review of randomized clinical trials. Br J Anaesth 110(Suppl 1):i113-120. doi:10.1093/bja/aet059

Brown GC, Bal-Price A (2003) Inflammatory neurodegeneration mediated by nitric oxide, glutamate, and mitochondria. Mol Neurobiol 27(3):325-355. doi:10.1385/MN:27:3:325

Calvo CF, Cesselin F, Gelman M, Glowinski J (2000) Identification of an opioid peptide secreted by rat embryonic mixed brain cells as a promoter of macrophage migration. Eur J Neurosci 12:2676-2684

Das M, Das DK (2008) Molecular mechanism of preconditioning. IUBMB Life 60(4):199-203. doi:10.1002/iub.31

de Vellis J, Cole R (2012) Preparation of mixed glial cultures from postnatal rat brain. Methods Mol Biol 814:49-59. doi:10.1007/978-1-61779-452-0 4

Goldsmith JR, Perez-Chanona E, Yadav PN, Whistler J, Roth B, Jobin C (2013) Intestinal epithelial cell-derived mu-opioid signaling protects against ischemia reperfusion injury through PI3K signaling. Am J Pathol 182(3):776-785. doi:10.1016/j.ajpath.2012.11.021

Goyagi T, Toung TJ, Kirsch JR, Traystman RJ, Koehler RC, Hurn PD, Bhardwaj A (2003) Neuroprotective kappa-opioid receptor agonist BRL 52537 attenuates ischemia-evoked nitric oxide production in vivo in rats. Stroke 34(6):1533-1538. doi:10.1161/01.STR.0000072512.30658.E7

Gross GJ, Baker JE, Hsu A, Wu HE, Falck JR, Nithipatikom K (2010) Evidence for a role of opioids in epoxyeicosatrienoic acid-induced cardioprotection in rat hearts. Am J Physiol Heart Circ Physiol 298(6):H2201-2207. doi:10.1152/ajpheart.00815.2009

Guedes AG, Papich MG, Rude EP, Rider MA (2007) Comparison of plasma histamine levels after intravenous administration of hydromorphone and morphine in dogs. J Vet Pharmacol Ther 30(6):516-522. doi:10.1111/j.1365-2885.2007.00911.x

Gwak MS, Li L, Zuo Z (2010) Morphine preconditioning reduces lipopolysaccharide and interferon-gamma-induced mouse microglial cell injury via delta 1 opioid receptor activation. Neuroscience 167(2):256-260. doi:10.1016/j.neuroscience.2010.02.017

Holownia A, Mroz RM, Wielgat P, Skiepko A, Sitko E, Jakubow P, Kolodziejczyk A, Braszko JJ (2009) Propofol protects rat astroglial cells against tert-butyl hydroperoxide-induced cytotoxicity; the effect on histone and CAMPresponse-element-binding protein (CREB) signalling. J Physiol Pharmacol 60(4):63-69

Hu Y, Wang S, Wang A, Lin L, Chen M, Wang Y (2015) Antioxidant and hepatoprotective effect of Penthorum chinense Pursh extract against t-BHP-induced liver damage in L02 cells. Molecules 20(4):6443-6453. doi:10.3390/molecules20046443

Hutchinson MR, Bland ST, Johnson KW, Rice KC, Maier SF, Watkins LR (2007) Opioid-induced glial activation: mechanisms of activation and implications for opioid analgesia, dependence, and reward. Sci World J 7:98-111. doi:10.1100/tsw.2007.230

Iwata-Ichikawa E, Kondo Y, Miyazaki I, Asanuma M, Ogawa N (1999) Glial cells protect neurons against oxidative stress via transcriptional up-regulation of the glutathione synthesis. J Neurochem 72(6):2334-2344

Jeong S, Kim SJ, Jeong C, Lee S, Jeong H, Lee J, Yoo KY (2012) Neuroprotective effects of remifentanil against transient focal cerebral ischemia in rats. J Neurosurg Anesthesiol 24(1):51-57. doi:10.1097/ANA.0b013e3182368d70

Knapp PE, Maderspach K, Hauser KF (1998) Endogenous opioid system in developing normal and jimpy oligodendrocytes: mu and kappa opioid receptors mediate differential mitogenic and growth responses. Glia 22(2):189-201

Kontos HA (1989) Oxygen radicals in CNS damage. Chem Biol Interact 72(3):229-255

Kreutzberg GW (1996) Microglia: a sensor for pathological events in the CNS Trends Neurosci 19(8):312-318

Lee YS, Park YC, Kim JH, Kim WY Yoon SZ, Moon MG, Min TJ (2012) Intrathecal hydromorphone added to hyperbaric bupivacaine for postoperative pain relief after knee arthroscopic surgery: a prospective, randomised, controlled trial. Eur J Anaesthesiol 29(1):17-21. doi:10.1097/ EJA.0b013e3283476055 
Madera-Salcedo IK, Cruz SL, Gonzalez-Espinosa C (2011) Morphine decreases early peritoneal innate immunity responses in Swiss-Webster and C57BL6/J mice through the inhibition of mast cell TNF-alpha release. J Neuroimmunol 232(1-2):101-107. doi:10.1016/j.jneuroim.2010.10.017

Maragakis NJ, Rothstein JD (2006) Mechanisms of disease: astrocytes in neurodegenerative disease. Nat Clin Pract Neurol 2(12):679-689. doi:10.1038/ ncpneuro0355

Mherekumombe MF, Collins JJ (2015) Patient-controlled analgesia for children at home. J Pain Symptom Manag 49(5):923-927. doi:10.1016/j. jpainsymman.2014.10.007

Milisav I, Poljsak B, Suput D (2012) Adaptive response, evidence of crossresistance and its potential clinical use. Int J Mol Sci 13(9):10771-10806. doi:10.3390/ijms130910771

Min TJ, Kim Jl, Kim JH, Noh KH, Kim TW, Kim WY, Lee YS, Park YC (2011) Morphine postconditioning attenuates ICAM-1 expression on endothelial cells. J Korean Med Sci 26(2):290-296. doi:10.3346/jkms.2011.26.2.290

Mucke L, Eddleston M (1993) Astrocytes in infectious and immune-mediated diseases of the central nervous system. FASEB J 7(13):1226-1232

Oosten AW, Oldenmenger WH, Mathijssen RH, van der Rijt CC (2015) A systematic review of prospective studies reporting adverse events of commonly used opioids for cancer-related pain: a call for the use of standardized outcome measures. J Pain 16(10):935-946. doi:10.1016/j.jpain.2015.05.006

Pearce B, Cambray-Deakin M, Murphy S (1985) Astrocyte opioid receptors: activation modifies the noradrenaline-evoked increase in [2-14C] deoxyglucose incorporation into glycogen. Neurosci Lett 55:157-160

Peters CE, Korcok J, Gelb AW, Wilson JX (2001) Anesthetic concentrations of propofol protect against oxidative stress in primary astrocyte cultures: comparison with hypothermia. Anesthesiology 94(2):313-321

Pourpak Z, Ahmadiani A, Alebouyeh M (2004) Involvement of interleukin1 beta in systemic morphine effects on paw oedema in a mouse model of acute inflammation. Scand J Immunol 59(3):273-277. doi:10.1111/j.0300-9475.2004.01396.x

Ricket A, Mateyoke G, Vallabh M, Owen C, Peppin J (2015) A pilot evaluation of a hydromorphone dose substitution policy and the effects on patient safety and pain management. J Pain Palliat Care Pharmacother 29(2):120-124. doi:10.3109/15360288.2015.1035829

Rostami F, Oryan S, Ahmadiani A, Dargahi L (2012) Morphine preconditioning protects against LPS-induced neuroinflammation and memory deficit. J Mol Neurosci 48(1):22-34. doi:10.1007/s12031-012-9726-4

Rush GF, Gorski JR, Ripple MG, Sowinski J, Bugelski P, Hewitt WR (1985) Organic hydroperoxide-induced lipid peroxidation and cell death in isolated hepatocytes. Toxicol Appl Pharmacol 78(3):473-483

Scheufler KM, Zentner J (2002) Total intravenous anesthesia for intraoperative monitoring of the motor pathways: an integral view combining clinical and experimental data. J Neurosurg 96(3):571-579. doi:10.3171/ jns.2002.96.3.0571
Shelat PB, Chalimoniuk M, Wang JH, Strosznajder JB, Lee JC, Sun AY, Simonyi A, Sun GY (2008) Amyloid beta peptide and NMDA induce ROS from NADPH oxidase and AA release from cytosolic phospholipase A2 in cortical neurons. J Neurochem 106(1):45-55. doi:10.1111/j.1471-4159.2008.05347.x

Son Y, Cheong YK, Kim NH, Chung HT, Kang DG, Pae HO (2011) Mitogenactivated protein kinases and reactive oxygen species: How can ROS activate MAPK pathways? J Signal Transduct 2011:792639. doi:10.1155/2011/792639

Turchan-Cholewo J, Dimayuga FO, Ding Q, Keller JN, Hauser KF, Knapp PE, Bruce-Keller AJ (2008) Cell-specific actions of HIV-Tat and morphine on opioid receptor expression in glia. J Neurosci Res 86:2100-2110

Verkhrataky A, Kirchhoff F (2007) NMDA receptors in Glia. Neuroscientist 1(13):2007

Vicente E, Degerone D, Bohn L, Scornavaca F, Pimentel A, Leite MC, Swarowsky A, Rodrigues L, Nardin P, de Almeida LM, Gottfried C, Souza DO, Netto CA, Gonçalves CA (2009) Astroglial and cognitive effects of chronic cerebral hypoperfusion in the rat. Brain Res 1251:204-212. doi:10.1016/j. brainres.2008.11.032

Watkins LR, Hutchinson MR, Rice KC, Maier SF (2009) The "toll" of opioidinduced glial activation: improving the clinical efficacy of opioids by targeting glia. Trends Pharmacol Sci 30(11):581-591. doi:10.1016/j. tips.2009.08.002

Wirz S, Wartenberg HC, Nadstawek J (2008) Less nausea, emesis, and constipation comparing hydromorphone and morphine? A prospective open-labeled investigation on cancer pain. Support Care Cancer 16(9):999-1009. doi:10.1007/s00520-007-0368-y

Yan LJ (2014) Positive oxidative stress in aging and aging-related disease tolerance. Redox Biol 2C:165-169. doi:10.1016/j.redox.2014.01.002

Zhang Z, Chen TY, Kirsch JR, Toung TJ, Traystman RJ, Koehler RC, Hurn PD, Bhardwaj A (2003) Kappa-opioid receptor selectivity for ischemic neuroprotection with BRL 52537 in rats. Anesth Analg 97(6):1776-1783

Zhang Y, Irwin MG, Wong TM (2004) Remifentanil preconditioning protects against ischemic injury in the intact rat heart. Anesthesiology 101(4):918-923

Zhang Y, Irwin MG, Lu Y, Mei B, Zuo YM, Chen ZW, Wong TM (2011) Intracerebroventricular administration of morphine confers remote cardioprotection-role of opioid receptors and calmodulin. Eur J Pharmacol 656(1-3):74-80. doi:10.1016/j.ejphar.2011.01.027

\section{Submit your manuscript to a SpringerOpen ${ }^{\odot}$ journal and benefit from:}

- Convenient online submission

- Rigorous peer review

- Immediate publication on acceptance

- Open access: articles freely available online

- High visibility within the field

- Retaining the copyright to your article

Submit your next manuscript at springeropen.com 